\title{
Erratum to: Reliable Rate Measurements for Active and Passive Hepatic Uptake Using Plated Human Hepatocytes
}

Yi-an Bi, ${ }^{1}$ Renato J. Scialis, ${ }^{1,2}$ Sarah Lazzaro, ${ }^{1}$ Sumathy Mathialagan, ${ }^{1}$ Emi Kimoto, ${ }^{1}$ Julie Keefer, ${ }^{1}$ Hui Zhang, ${ }^{1}$ Anna M. Vildhede, ${ }^{1}$ Chester Costales, ${ }^{1}$ A. David Rodrigues, ${ }^{1}$ Larry M. Tremaine, ${ }^{1}$ and Manthena V. S. Varma ${ }^{1,3}$

\section{Erratum to: AAPS J}

DOI 10.1208/s12248-017-0051-2

The middle initial of the second author's name was missing in the original article. The second author's complete name is "Renato J. Scialis" as listed in this erratum. The original article was corrected.

The online version of the original article can be found at http:// dx.doi.org/10.1208/s12248-017-0051-2.

\footnotetext{
${ }^{1}$ Pharmacokinetics Dynamics and Metabolism, Pfizer Global Research and Development, Pfizer Inc., Groton, Connecticut, USA.

${ }^{2}$ Present Address: Department of Metabolism and Pharmacokinetics, Bristol-Myers Squibb Research and Development, Princeton, New Jersey, USA.

${ }^{3}$ To whom correspondence should be addressed. (e-mail: manthena.v.varma@pfizer.com)
} 